\title{
Role of sulphasalazine in the aetiology of folate deficiency in ulcerative colitis
}

\author{
CHRISTINE M SWINSON, JANET PERRY, M LUMB, AND A J LEVI \\ From the Departments of Gastroenterology and Haematology, Northwick Park Hospital and \\ Clinical Research Centre, Harrow, Middlesex
}

SUMMARY Only two $(2.5 \%)$ of 80 outpatients with histologically proven ulcerative colitis had folate deficiency associated with anaemia or macrocytosis. Mean folate absorption, measured using $3 \mu \mathrm{g} / \mathrm{kg}$ body weight of a tritium-labelled physiological folate derivative, 5-methyltetrahydroteroylglutamic acid, in six newly diagnosed patients was $76.7 \%$ (normal $>95 \%$ ) but fell to $69 \cdot 4 \%$ after three months' treatment with sulphasalazine. Mean difference in individual patients was $7.5 \% \pm 5 \cdot 2 \%$ (SD) $(\mathrm{P}<0.02)$. Mean folate absorption in four patients with megaloblastic anaemia or macrocytosis which developed during treatment with sulphasalazine was $66 \cdot 3 \%$. This rose to $82.4 \%$ after the drug was stopped. Mean difference in individual patients was $16.6 \pm 6.6 \%$ (SD) $(\mathrm{P}<0.001)$. All patients who developed anaemia or macrocytosis with sulphasalazine had additional reasons for folate deficiency. These included coeliac disease, severe nutritional deficiencies, and haemolysis. It was concluded that sulphasalazine impairs folate absorption but this only becomes significant if other reasons for folate deficiency are also present.

Megaloblastic anaemia due to folate deficiency is not an accepted complication of sulphasalazine treatment, although there are a few case reports of the association. ${ }^{1-4}$ Two patients who developed macrocytic megaloblastic anaemia due to folate deficiency during treatment with sulphasalazine prompted this study. A group of patients with ulcerative colitis was investigated to assess the incidence and cause of folate deficiency and the role of sulphasalazine in aetiology.

\section{Methods}

\section{P A T I E N T S}

Eighty-three outpatients with histologically proven ulcerative colitis who attended consecutive gastrointestinal outpatient clinics at Northwick Park Hospital had samples taken for a full blood count, reticulocyte count, haptoglobins, B12, folate, red cell folate, and biochemical screen including iron and iron binding capacity. Three patients were receiving folic acid supplements and their results were subsequently excluded. Sixty $(75 \%)$ of the remaining 80 patients were being treated with sulphasalazine in doses of $2-4 \mathrm{~g} /$ day. Six of the remaining $20(25 \%)$ patients were newly

Received for publication 27 December 1980 diagnosed.

Two patients who were recognised before the study started and two patients identified by the study, all with megaloblastic anaemia or macrocytosis due to folate deficiency which developed during treatment with sulphasalazine, underwent detailed studies as inpatients on a metabolic ward to assess the causes of their folate deficiency. These studies included two measurements of folate absorption, one initially while the patient was being treated with sulphasalazine and one at least two months after treatment was stopped; jejunal biopsy at the time of each folate absorption study; and dietary assessment at the time of the first absorption study.

Folate absorption was also measured in six newly diagnosed patients, and repeated after three months' treatment with sulphasalazine. In one patient it was also measured with the first dose of sulphasalazine. All patients underwent jejunal biopsies to exclude coeliac disease.

Haematological and biochemical parameters were measured routinely in the hospital laboratories. Red cell indices were corrected for trapped plasma. Serum B12, folate, and red cell folate were assayed microbiologically.

Folate absorption was measured directly. Faecal excretion of a tritium-labelled physiological folate derivative, 5-methyltetrahydrop- 
teroylglutamic acid, given orally in a physiological dose of $3 \mu \mathrm{g} / \mathrm{kg}$, was measured using the method described by Steytler. ${ }^{5}$ Previous unpublished studies at this hospital on volunteers, all without bowel disease, had shown that in this dose more than $95 \%$ of this folate derivative is absorbed. When folate absorption was measured in patients receiving sulphasalazine, a $1 \mathrm{~g}$ dose was given with the tritiated folate derivative.

Jejunal biopsies were taken using a Crosby Capsule small bowel biopsy capsule screened beyond the duodenal-jejunal flexure. The specimens were assessed routinely in the hospital pathology laboratory. Assessment included subjective opinion and objective measurement of intraepithelial lymphocyte counts and morphometry.

Dietary folate was assessed by qualified dieticians using the tables published by Hurdle et al.$^{6}$

Standard statistical techniques (multiple regression analysis, $\chi^{2}$ with Yates' correction for small numbers, the paired $t$ test, analysis of variance and linear contrast between means ${ }^{7}$ ) were used with the help of members of the Division of Computing and Statistics, Clinical Research Centre.

\section{Results}

O U T P A T IENT S UR V EY

Eighteen $(22.5 \%)$ of the patients were macrocytic with a mean cell volume (MCV) above the upper limit of normal, $92 \mathrm{fl}$. All these patients were being treated with sulphasalazine $(\mathrm{P}<0 \cdot 05)$. The mean MCV was higher $(p<0.001)$ in the treated group, but the mean MCV of both groups fell within the normal range (Fig. 1).

Twenty-five of $59(42.4 \%)$ patients in the group treated with sulphasalazine had a raised reticulocyte count (normal range $<2 \%$ ) compared with one of $15(6.7 \%)$ in the untreated group $(\mathrm{P}<0.05)$. The highest reticulocyte count recorded was $\mathbf{4 \cdot 2} \%$. Reticulocyte count was directly $(P<0.001)$ related to the dose of sulphasalazine (Table 1). The proportion of patients with absent

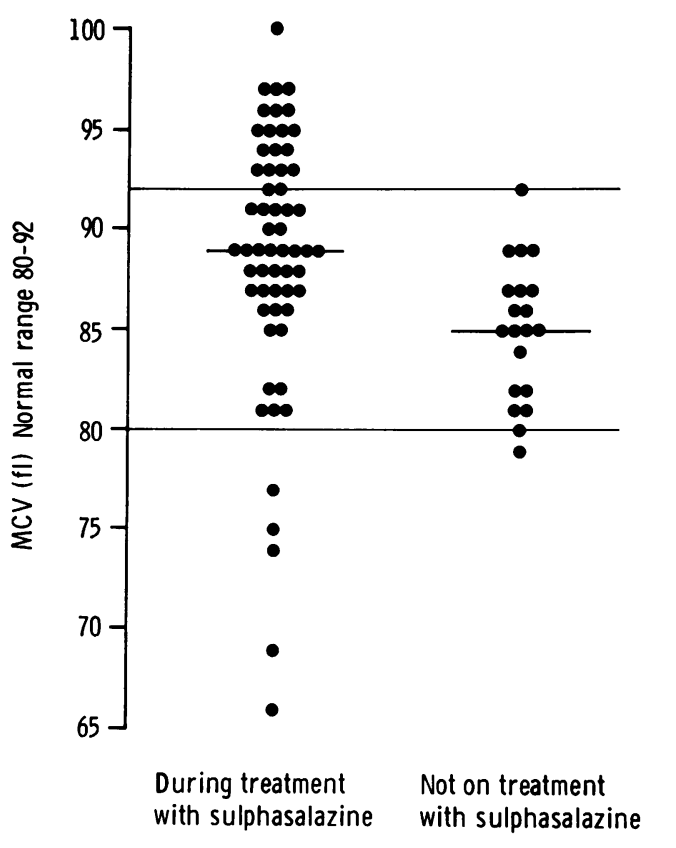

Mean $88.6 \pm 6.7$ (s.d.) (60) Mean $85.1 \pm 3.5$ (s.d.) (20)

$$
\longleftarrow \mathrm{p}<0.001 \longrightarrow
$$

Fig. $1 M C V$ during treatment and not on treatment with sulphasalazine.

haptoglobins or levels of $80 \mathrm{mg} / 100 \mathrm{ml}$ or less (normal range $30-200 \mathrm{mg} / 100 \mathrm{ml}$ ) did not differ between the two groups.

MCV was inversely related to serum folate $(P<0.01)$ and directly related to serum iron $(P<0.01)$, but not related to reticulocyte count, red cell folate or serum B12.

Only two $(2 \cdot 5 \%)$ patients had a low serum folate or red cell folate with megaloblastic anaemia or macrocytosis, although eight $(10.0 \%)$ other patients had a low red cell folate. Neither serum nor red cell folate was related to the dose of sulphasalazine.

Table 1 Reticulocyte count, serum folate and red cell folate in relation to dose of sulphasalazine

\begin{tabular}{|c|c|c|c|}
\hline $\begin{array}{l}\text { Daily dose of } \\
\text { Sulphasalazine }(g)\end{array}$ & $\begin{array}{l}\text { Mean reticulocyte } \\
\text { count }\end{array}$ & Mean serum folate & Mean red cell folate \\
\hline $\begin{array}{l}\text { None } \quad(20)^{*} \\
2 \quad(15) \\
3 \\
4 \quad(34) \\
\text { One way analysis of } \\
\text { variance between groups } \\
\text { then linear contrast } \\
\text { between means }\end{array}$ & $\begin{array}{l}1.1 \pm 0.7(\mathrm{SD})(15) \\
1.5 \pm 0.8(\mathrm{SD})(14) \\
1.6 \pm 1.0(\mathrm{SD})(34) \\
2.7 \pm 0.9(\mathrm{SD})(11) \\
\mathrm{P}<0.001\end{array}$ & $\begin{array}{l}6 \cdot 7 \pm 3 \cdot 5 \text { (SD) (20) } \\
5 \cdot 9 \pm 3 \cdot 8 \text { (SD) (15) } \\
7 \cdot 7 \pm 4 \cdot 6 \text { (SD) (34) } \\
3 \cdot 8 \pm 1 \cdot 4 \text { (SD) (11) } \\
\text { NS }\end{array}$ & $\begin{array}{l}247 \pm 127 \text { (SD) (19) } \\
272 \pm 116 \text { (SD) (15) } \\
415 \pm 252 \text { (SD) (32) } \\
282 \pm 143(\text { SD) }(10) \\
\text { NS }\end{array}$ \\
\hline
\end{tabular}

* Figures in parentheses indicate numbers of patients. 
Five of $19(26 \cdot 3 \%)$ patients with a low red cell folate were in the untreated group compared with four of $57(7.0 \%)$ in the groups receiving sulphasalazine $(P<0.05)$. Within the untreated group, three of the six newly diagnosed patients $(50 \%)$ had a low red cell folate compared with two of $13(15.4 \%)$ of the others $(P<0.05)$.

F OLATE A B S OR P T ION STUDIES

All 10 patients had impaired folate absorption, and in all but one patient this was impaired further by sulphasalazine.

Mean folate absorption in the six newly diagnosed patients was $76.7 \%$ but fell to $69.4 \%$ after three months' treatment with sulphasalazine. Mean difference in individual patients was $7.5 \% \pm 5.2 \%$ (SD) $(\mathrm{P}<0.02)$.

Mean folate absorption in the four patients with megaloblastic anaemia or macrocytosis associated with sulphasalazine was $66 \cdot 3 \%$. This rose to $82.4 \%$ after the drug was stopped. Mean difference in individual patients was $16.1 \% \pm 6.6 \%$ (SD) $(\mathbf{P}<0.01)$ (Fig. 2).

In one patient folate absorption measured with the first dose of sulphasalazine was $70 \%$ compared with $89 \%$ before treatment and $77 \%$ after three months' treatment.

\section{O T H E R S T U D I E S}

Table 2 shows the severity of the haematological abnormalities which developed with sulphasalazine in the four folate deficient patients. Patient 1 was treated with folic acid in a pharmacological dose of $5 \mathrm{mg}$ three times a day while sulphasalazine was continued. Her haematological abnormalities resolved completely. The other three patients did not receive folate supplements, but stopped sulphasalazine. Their haematological abnormalities also resolved completely.

Figure 3 shows serial results from patient 2 to illustrate the rate of development of haematological abnormalities with sulphasalazine and the rate of resolution after the drug is stopped. This patient's reticulocyte count was $3.2 \%$ when his

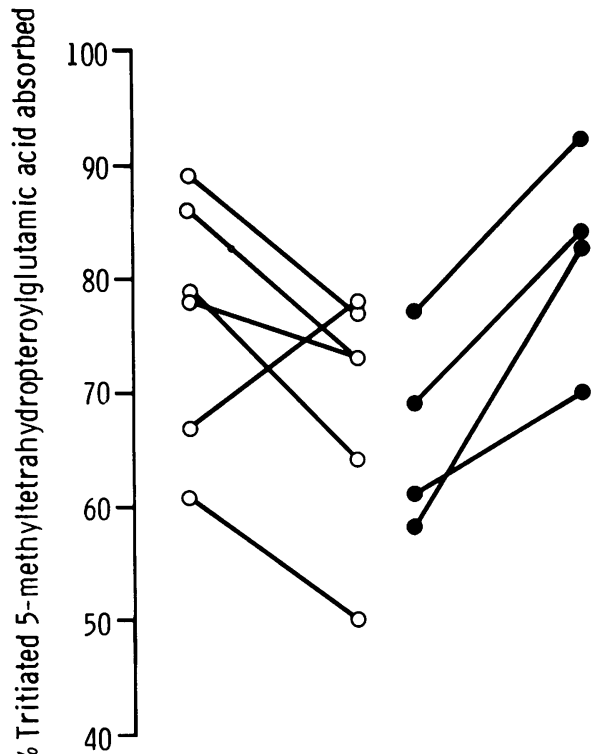

$$
\begin{array}{lll}
\text { Before } & \text { During } & \text { After } \\
\text { sulpha- } & \text { treatment with } & \text { sulpha- } \\
\text { salazine } & \text { sulphasalazine } & \text { salazine }
\end{array}
$$

$$
\begin{array}{ll}
\text { Mean difference } & \text { Mean difference } \\
7.5 \% \pm 5.2 \% \text { (s.d.) (6) } & 16.1 \% \pm 6.6 \% \text { (s.d.) (4) } \\
p<0.02 & p<0.01
\end{array}
$$

Fig. 2 Folate absorbtion in patients before, during, and after treatment with sulphasalazine. $\bigcirc$ Newly diagnosed patients with ulcerative colitis. Previously diagnosed patients developing folate deficiency in association with sulphasalazine therapy.

haematological abnormalities were maximal and fell to the normal range when sulphasalazine was stopped.

Each of these four patients had other reasons for folate deficiency in addition to folate malabsorption caused by sulphasalazine. All had

\begin{tabular}{|c|c|c|c|c|c|}
\hline \multirow[t]{2}{*}{ Parameter } & \multirow[t]{2}{*}{ Normal range } & \multicolumn{4}{|l|}{ Patient } \\
\hline & & 1 & 2 & 3 & 4 \\
\hline $\begin{array}{l}\text { Hb (g/dl) } \\
\text { MCV (f) } \\
\text { Reticulocyte count (\%) } \\
\text { Haptoglobins (mg/ml) } \\
\text { Serum folate (ng/ml) } \\
\text { RCF (ng/ml) } \\
\text { Marrow }\end{array}$ & $\begin{array}{c}12 \cdot 3-17 \cdot 0 \\
80-92 \\
<2 \\
30-200 \\
3-15 \\
145-450\end{array}$ & $\begin{array}{l}9 \cdot 8 \\
114 \\
5 \cdot 8 \\
240 \\
1 \cdot 6 \\
36 \\
\text { Megaloblastic }\end{array}$ & $\begin{array}{l}12 \cdot 8 \\
110 \\
3 \cdot 2 \\
140 \\
1 \cdot 6 \\
151 \\
\text { Megaloblastic }\end{array}$ & $\begin{array}{l}11 \cdot 5 \\
112 \\
2 \cdot 8 \\
\text { Absent } \\
<1 \cdot 0 \\
154 \\
\text { Megaloblastic } \\
\text { Iron deficient }\end{array}$ & $\begin{array}{l}12 \cdot 4 \\
94 \\
3 \cdot 0 \\
240 \\
2 \cdot 2 \\
66 \\
\text { Normal }\end{array}$ \\
\hline
\end{tabular}
raised reticulocyte counts indicative of haemolysis. Patient 1 had a chest infection associated with lobular collapse and consolidation which

Table 2 Severity of normal haematological abnormalities which developed with sulphasalazine in four folate deficient patients 


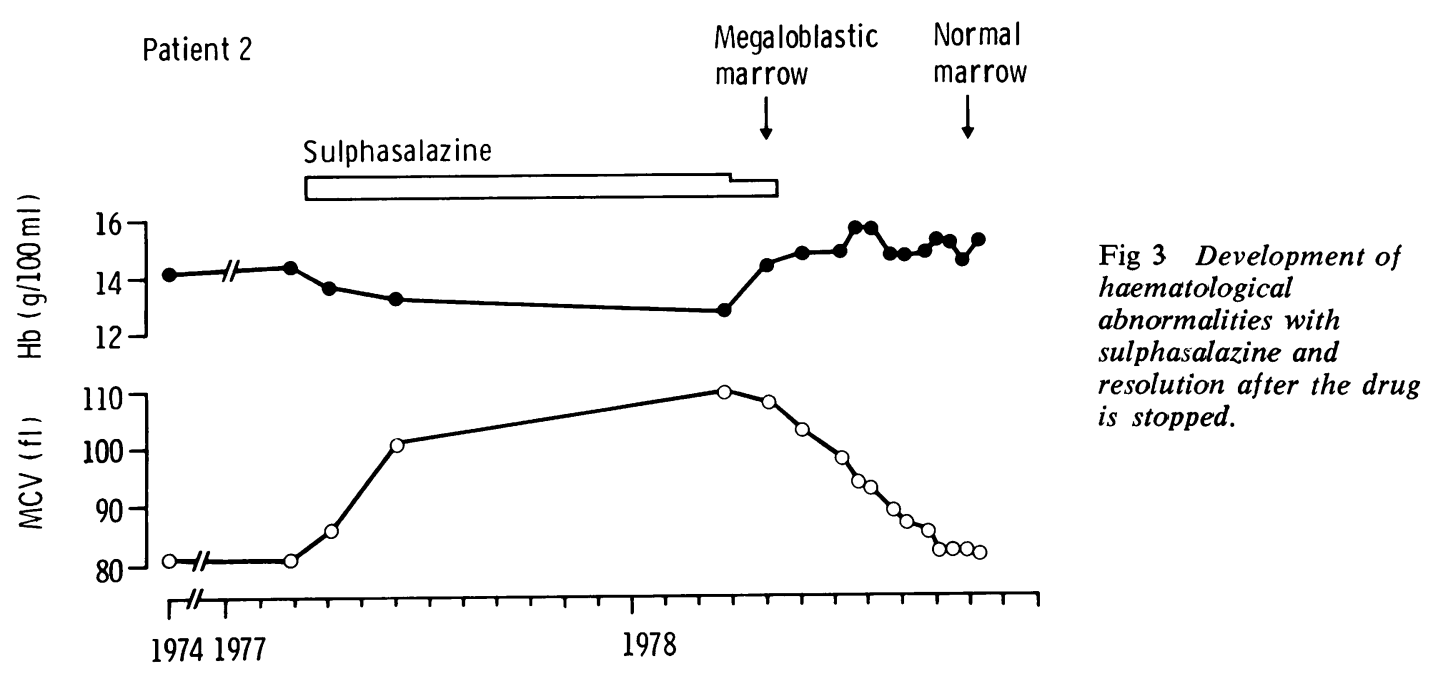

led to a protracted period of intercurrent illhealth; patient 2 had a flat jejunal biopsy characteristic of adult coeliac disease; patient 3 had a low dietary folate intake of $100 \mu \mathrm{g} /$ day, dietary iron deficiency and active tuberculosis; and patient 4 had a borderline dietary folate intake of $180 \mu \mathrm{g} /$ day. On her initial jejunal biopsy patient 1 had a raised intraepithelial lymphocyte count with subjective and morphometric evidence of a non-specific mild partial villous atrophy, but these changes had resolved when the biopsy was repeated and were not thought to indicate coeliac disease.

None of the six newly diagnosed patients had evidence of coeliac disease but three $(50 \%)$ had non-specific minor abnormalities on their initial jejunal biopsies. All three had raised intraepithelial lymphocyte counts and two also had subjective and morphometric evidence of a mild partial villous atrophy. Changes in all but one patient had resolved completely when the biopsies were repeated.

Three newly diagnosed patients had a low red cell folate, but after three months' treatment with sulphasalazine in maximum tolerated dose $(2-4 \mathrm{~g} /$ day) the level was normal in two of these patients, despite further impairment in folate absorption.

\section{Discussion}

The incidence of significant folate deficiency in patients with ulcerative colitis attending the gastroenterological clinic at Northwick Park Hospital is low. Only $2.5 \%$ (two of 80 ) patients had anaemia associated with a low serum or red cell folate, although another eight (10\%) had a low red cell folate.

This incidence of folate deficiency is similar to the $3.4 \%$ calculated from Pounder et al. ${ }^{8}$ who found two patients with a low serum folate in a group of 59 patients with ulcerative colitis not receiving folate supplements. In contrast, in studies of patients with inflammatory bowel disease, Franklin et al. ${ }^{9}$ found a $63 \%$ incidence (49 of 78) of low serum folate in a retrospective study of patients in hospital, and Elsborg et al. ${ }^{10}$ a $59 \%$ incidence of low serum and red cell folate in those patients with ulcerative colitis in 216 consecutive outpatients. This latter group was thought to have a borderline dietary intake of folate, unlike the group described here, or by Pounder et al. ${ }^{8}$

Macrocytosis is an unreliable indicator of folate deficiency in patients receiving sulphasalazine. Minor haemolysis is a well-recognised doserelated effect of the drug. ${ }^{8}$ This results in a higher proportion of younger, larger cells in the circulation reflected by a rise in MCV and sometimes an increased reticulocyte count. A higher proportion of our patients receiving sulphasalazine had a raised reticulocyte count, compared with the untreated group. Haptoglobin estimation was less sensitive in detecting these minor degrees of haemolysis which occurred with sulphasalazine. Conversely, coincidental iron deficiency may mask the effect of folate deficiency on $\mathrm{MCV}$ in patients with active disease.

Dietary intake of folate may be impaired by chronic ill-health; and changes in body stores of folate are usually reflected more accurately by changes in red cell folate compared with 
serum folate. The most plausible reason why $50 \%$ (three of six) of our newly diagnosed patients had a low red cell folate compared with only $15.4 \%$ (two of 13 ) of the other untreated patients, is reduced dietary intake during a period of ill-health before diagnosis. Return to normal of red cell folate during treatment with sulphasalazine in two of the three patients was probably because of increased dietary intake of folate with remission of the disease, which overcame the further impairment in absorption caused by sulphasalazine. The average British diet contains 200-300 $\mu \mathrm{g}$ total folate per day, not much above the recommended daily intake of $200 \mu \mathrm{g},{ }^{11}$ so even a minor impairment of absorption may have a significant effect during a prolonged period of dietary deficiency. However, the minor haemolysis caused by sulphasalazine may make red cell folate an unreliable indicator of body stores of folate in patients treated with the drug because the younger red cells which appear in the circulation have a higher folate content compared with older cells.

Our finding of impaired folate absorption in patients with ulcerative colitis, which is impaired further by sulphasalazine, confirms earlier work of Franklin et al. ${ }^{9}$ They also used a direct method of measurement but used folic acid, not a physiological derivative.

Salem et al. ${ }^{12} 13$ have shown that minor jejunal abnormalities in ulcerative colitis, first described by them and confirmed in our study, correlate with other abnormalities of small intestinal function and the activity of the colitis. Thus the impaired folate absorption could result from these minor jejunal abnormalities.

Our results in one patient indicate that sulphasalazine has an acute inhibitory effect on folate absorption. This is consistent with competitive inhibition of folate enzymes, which has been proposed as another mechanism of folate malabsorption caused by sulphasalazine. ${ }^{914}$

Only occasional patients, two of $60(3.3 \%)$ in our study, plus two identified previously, develop anaemia or macrocytosis due to folate deficiency with sulphasalazine. Our four patients all had several reasons for folate deficiency. All had folate malabsorption caused by sulphasalazine and minor haemolysis, combined with coeliac disease, or dietary deficiency, or other intercurrent disease. The anaemia or macrocytosis resolved when sulphasalazine was stopped. Thus, in most patients with ulcerative colitis receiving sulphasalazine, folate malabsorption and increased folate requirements secondary to minor haemolysis are clinically insignificant, but, when other reasons for folate deficiency are present, sulphasalazine may be of crucial importance in tipping the balance to clinically significant folate deficiency and megaloblastic anaemia.

\section{Conclusions}

Folate deficiency is not a significant clinical problem in outpatients with ulcerative colitis and adequate dietary intakes of folate, whether or not they are treated with sulphasalazine. Newly diagnosed patients with active disease are more likely to be folate deficient. This is probably due to a combination of impaired dietary intake of folate during a period of chronic ill-health before diagnosis and minor folate malabsorption. Sulphasalazine impairs folate absorption further by acute inhibition, but in most patients this is overcome by increased dietary intake of folate as the disease is ireated and general health improves. The small number of patients who develop folate deficiency with sulphasalazine are likely to have other reasons for folate deficiency such as coeliac disease, severe nutritional deficiencies, or haemolysis. When there are other reasons for folate deficiency, sulphasalazine may be the critical factor which precipitates folate deficiency and megaloblastic anaemia.

We are grateful to the Departments of Haematology and Clinical Chemistry, Northwick Park Hospital, and members of the Division of Computing and Statistics for their help and cooperation in carrying out this study.

\section{References}

${ }^{1}$ Schneider RE, Beeley L. Megaloblastic anaemia associated with sulphasalazine treatment. $\mathrm{Br}$ Med J 1977; 1:1638-9.

2Kane SP, Boots MA. Megaloblastic anaemia associated with sulphasalazine treatment. $\mathrm{Br}$ Med J 1977; 2:1287-8.

${ }^{3}$ Lederer J, Kumps J. Mécanisme d'action de la salicylazosulfapyridine (Salazopyrine) sur l'activité de l'acide folique dans la rectocolite ulcérohémorragique. Acta Gastroenterol Belg 1979; 42: 73-81.

${ }^{4}$ van Hees PAM. Clinical and pharmacological aspects of sulphasalazine. (Thesis) Gist-Brocades nv Delft, 1979: 164-7.

5Steytler JG. The assay of tritium-labelled folate in faeces by the oxygen flask combustion technique followed by liquid scintillation counting. J Clin Pathol 1974; 27:844-7.

${ }^{6}$ Hurdle ADF, Barton D, Searles IH. A method for measuring folate in food and its application to a hospital diet. Am J Clin Nutr 1968; 21:1202-7. 
${ }^{7}$ Cochran WG, Cox GM. Experimental designs, Second edition. New York: Wiley, 1957.

${ }^{8}$ Pounder RE, Craven ER, Henthorn JS, Bannalyne JM. Red cell abnormalities associated with sulphasalazine maintenance therapy for ulcerative colitis. Gut 1975; 16:181-5.

${ }^{9}$ Franklin JL, Rosenberg IH. Impaired folic acid absorption in inflammatory bowel disease: effects of salicylazosulfapyridine (Azulfidine). Gastroenterology 1973; 64:517-25.

${ }^{10}$ Elsborg L, Larsen L. Folate deficiency in chronic inflammatory bowel diseases. Scand J Gastroenterol 1979; 14:1019-24.
11Report by the Committee on Medical Aspects of Food Policy. Recommended daily amounts of food energy and nutrients for groups of people in the United Kingdom. London: HMSO, 1979.

${ }^{12}$ Salem SN, Truelove SC, Richards WCD. Smallintestinal and gastric changes in ulcerative colitis: a biopsy study. Br Med J 1964; 1:394-8.

${ }^{13}$ Salem SN, Truelove SC. Small-intestinal and gastric abnormalities in ulcerative colitis. $\mathrm{Br}$ Med J 1965; 1:827-31.

${ }^{14}$ Selhub J, Dhar GJ, Rosenberg IH. Inhibition of folate enzymes by sulphasalazine. J Clin Invest 1978; 61:221-4. 